\title{
Cytoreductive surgery (SRC) and hyperthermic intraperitoneal chemotherapy (HIPEC) for treatment of peritoneal carcinomatosis: Our initial experience and technical details
}

Koray Topgül' ${ }^{1}$, Mehmet Bilge Çetinkaya ${ }^{2}$, N. Çiğdem Arslan³ ${ }^{3}$ Mustafa Kemal Güll ${ }^{4}$, Murat Çan ${ }^{5}$, Mahmut Fikret Gürsel ${ }^{5}$, Dilek Erdem ${ }^{4}$, Zafer Malazgirt ${ }^{5}$

\section{ABSTRACT}

'Department of General Surgery, İstanbul Kemerburgaz University Faculty of Medicine, İstanbul, Turkey

${ }^{2}$ Department of Gynecology and Obstetrics, Ondokuz Mayıs University Faculty of Medicine, Samsun, Turkey

${ }^{3}$ Clinic of General Surgery, Tatvan State Hospital, Bitlis, Turkey

${ }^{4}$ Clinic of Medical Oncology, Medical Park Samsun Hospital, Samsun, Turkey

${ }^{5} \mathrm{Clinic}$ of General Surgery, Medical Park Samsun Hospital, Samsun, Turkey

\section{Address for Correspondence}

\section{Koray Topgül}

İstanbul Kemerburgaz Üniversitesi Tip Fakültesi, Genel Cerrahi Anabilim Dalı, İstanbul, Türkiye Phone: +905324466411 e-mail:ktopgul@gmail.com

Received: 17.11.2014

Accepted: 22.01.2015

CCopyright 2015 by Turkish Surgical Association Available online at www.ulusalcerrahidergisi.org
Objective: The aim of this study is to present our initial experience in peritoneal carcinomatosis treatment and the technical details of cytoreductive surgery (CRS) and hyperthermic intraperitoneal chemotherapy (HIPEC) in the light of current literature.

Material and Methods: Data of 27 consecutive patients who were treated with CRS and HIPEC for peritoneal carcinomatosis in Medical Park Samsun Hospital, between November 2012 and September 2014 were retrospectively reviewed. Treatment indication and management were evaluated at the multidisciplinary oncology council. All patients underwent CRS and HIPEC with the aim of complete cytoreduction. Patients with unresectable disease and/or palliative surgery were excluded from analysis. Perioperative complications were classified according to Clavien-Dindo classification, and HIPEC-related side effects were identified using National Cancer Institute Common Terminology Criteria for Adverse Events (CTCAE) criteria. Demographic, clinical and histopathological data of the patients were analyzed.

Results: The mean age was 54 (32-72). Nineteen patients were female. The origin of peritoneal carcinomatosis was colorectal cancer in 12 patients, ovarian cancer in 12 patients, gastric cancer in 2 patients and pseudomyxoma peritonei in 1 patient. The mean Peritoneal Carcinomatosis Index was 12 (3-32), with a mean operative time of 420 (300-660) minutes. Perioperative morbidity, HIPEC-related toxicity and perioperative mortality were observed in eight (30\%), one (3.7\%) and four patients (14.8\%), respectively. During a mean follow up of 13 (1-22) months, overall and disease-free survival rates were $95.8 \%$ and $82.6 \%$, respectively. Two patients with colorectal cancer (after 9 and 12 months) and one patient with ovarian cancer (after 11 months) had intra-abdominal recurrence. One patient with ovarian cancer had liver metastases 13 months after surgery, and underwent resection of segments 6-7. The remaining patients are being followed-up without any recurrence.

Conclusion: Cytoreductive surgery and HIPEC have favorable results in the treatment of patients with peritoneal carcinomatosis. Compatible with the literature, surgical outcomes of the presented series are encouraging for this treatment modality that have been recently popularized in our country. Careful perioperative evaluation, proper patient selection and multidisciplinary approach are essential for success in curative treatment of peritoneal carcinomatosis.

Keywords: Peritoneal carcinomatosis, cytoreductive surgery, hipec

\section{INTRODUCTION}

Peritoneal carcinomatosis (PC) is a common clinical presentation detected in advanced stages of gastrointestinal and gynecological cancer as well as peritoneal mesothelioma, which influences long-term survival. About $15 \%$ of patients with colorectal cancer (CRC) have PC at the time of diagnosis, and only a 6-month survival can be achieved with palliative treatment in these patients $(1,2)$. Although it was traditionally considered as stage 4 disease offering only palliative treatment, Spratt $(3,4)$ and Sugarbaker suggested the idea that more promising results can be achieved when PC is approached as a locally advanced cancer rather than metastatic disease, in the 80s (5). Current application and published positive data on cytoreductive surgery (CRS) and hyperthermic intraperitoneal chemotherapy (HIPEC) popularized the concept of curative approach for PC.

Cytoreductive surgery is the procedure defined by Sugarbaker (5) that includes a number of organ resections and peritonectomy. The aim is complete removal of tumor tissue, organ and/or the peritoneal surfaces without leaving any visible tumor in the abdominal cavity. Intraperitoneal chemotherapy applied following surgery aims to complete macroscopic cytoreduction to microscopic cytoreduction. With intraperitoneal administration, therapeutic concentrations in the peritoneal cavity could be achieved with lower doses of chemotherapeutic drugs, thus obtaining similar effects with less systemic side effects. The pharmacokinetic activity of intraperitoneal administration is better than that of systemic intravenous chemotherapy (6). Hyperthermia increases the effectiveness of intraperitoneal chemotherapy by increasing peritoneal blood flow, direct cytotoxicity and effects on tumor microenvironment (7). Therefore, it is recommended that intraperitoneal chemotherapy applied at 40 to $42^{\circ} \mathrm{C}$, at which maximum thermal chemo-sensitization is achieved (8). Today, HIPEC can be applied in a constant temperature and pressure with the aid of modern equipments. 
In order to achieve successful results in the treatment of PC, it is imperative that the three main applications of this multidisciplinary approach; appropriate patient selection, complete cytoreduction, and perioperative intraperitoneal chemotherapy followed by postoperative chemotherapy should be implemented flawlessly. Proper patient selection, aggressive surgery and intraperitoneal chemotherapy prolong survival in this patient group with a poor natural progression, making curative approach possible (9).

In this article, we aimed to present the technical details of CRS and HIPEC applications, and share the results of patients treated with SRC and HIPEC for PC at our center along with the current literature.

\section{MATERIAL AND METHODS}

Prospectively collected data of 27 consecutive patients who were treated with curative intent for PC with CRS and HIPEC in Samsun Medical Park Hospital General Surgery Department between November 2012 and September 2014 were analyzed. Preoperative staging was done with thoracoabdominal-computed tomography (CT) and positron emission tomography (PET)/ $\mathrm{CT}$ in all patients and tumor markers were evaluated. A group of patients was evaluated with diagnostic laparoscopy for resectability, and treatment strategy was identified accordingly. Indications for treatment and strategy were established in multidisciplinary oncology meetings. Candidate patients for curative surgery were selected by aiming at complete cytoreduction. Radiologic mesenteric root involvement, retroperitoneal invasion, massive pancreatic capsule involvement, small bowel involvement possibly requiring resection of more than one-third of the total length, unresectable liver metastases or extra-abdominal metastases, and/or patients with an ECOG performance score of $\geq 3$ were selected for palliative approach. Candidate patients for surgery and their relatives were informed on the details of the procedure, possible complications and requirement for ostomy (permanent/temporary) and organ resection, and their consents were obtained. Nutritional status and general condition of surgical candidates were evaluated; patients who needed improvement in blood levels or nutritional parameters were hospitalized in the preoperative period and prepared for surgery. Perioperative surgical complications were classified according to ClavienDindo (10), and HIPEC-related side effects according to Common Terminology Criteria for Adverse Events (CTCAE) (11). All patients were followed-up with CT and tumor markers after hospital discharge at regular intervals. Patients with recurrent disease and mortality were detected. Demographic, clinical and histopathological data were analyzed retrospectively.

\section{Technique}

\section{Cytoreductive surgery}

All patients received deep vein thrombosis prophylaxis with preoperative low molecular weight heparin, and anti-embolic stockings. Perioperative urinary catheter and urethral catheterization was performed in necessary cases. Cefuroxime sodium and metronidazole was used for antibiotic prophylaxis. Antibiotic doses were repeated once in every three hours. Surgery was performed in the Lloyd-Davis position. A midline incision extending from the xiphoid to the pubis was used. Scars due to a previous midline incision and the umbilicus were excised due to a possibility of tumor implant. In patients requiring upper quadrant diaphragmatic (right or left) peritonectomy, the xiphoid and epigastric fat pad were excised. After entering the abdomen, as- cites and mucin decompression was performed, if any. Figure 1 depicts the operative image of a patient with pseudomyxoma peritonei (PMP) who underwent mucin decompression. Thompson retractor was used for retraction. Disease dissemination was scored according to the Peritoneal Carcinomatosis Index (PCI) defined by Sugarbaker with intraoperative staging (Figure 2) (12). In case of presence of unresectability criteria not detected by radiologic evaluations, palliative interventions (stoma, debulking, palliative resection) was performed, HIPEC was not applied to these patients, and these patients were excluded from analysis. Figure 3 shows a patient judged to be unresectable due to extensive small intestine involvement.

Aggressive organ and peritoneal resection was performed in all procedures in patients selected for cytoreductive surgery aiming at complete macroscopic cytoreduction (13). After decompression of ascites or mucin, all organs and peritoneal surfaces that require resection were determined with abdominal exploration. Surgical strategy was created. The omentectomy was usually made initially (omental cake). All peritoneal surfaces with disease involvement were stripped (Figure 4). Peritonectomy was not applied outside the unaffected peritoneal surfaces except in PMP. Peritonectomy was performed by using round tipped cautery at high degrees. This provided both control of small vascular bleedings and destruction of tumor tissue. In patients with pseudomyxoma peritonei, complete visceral and parietal peritonectomy was also applied in unaffected areas. Tumor nodules on the liver surface were removed by stripping off Glisson's capsule (Figure 5). To achieve a complete right upper quadrant diaphragmatic peritonectomy, the liver was fully mobilized and rotated medially. Diaphragmatic peritoneum was completely removed. In patients with diaphragmatic injury or those requiring partial resection, the injury was repaired after inflating the lung. Chest tubes were not inserted in any patients. Cholecystectomy was performed. Hepatodoudenal ligament and the small omentum were removed in selected cases. The small omentum and gastrocolic ligament was opened regardless of disease involvement

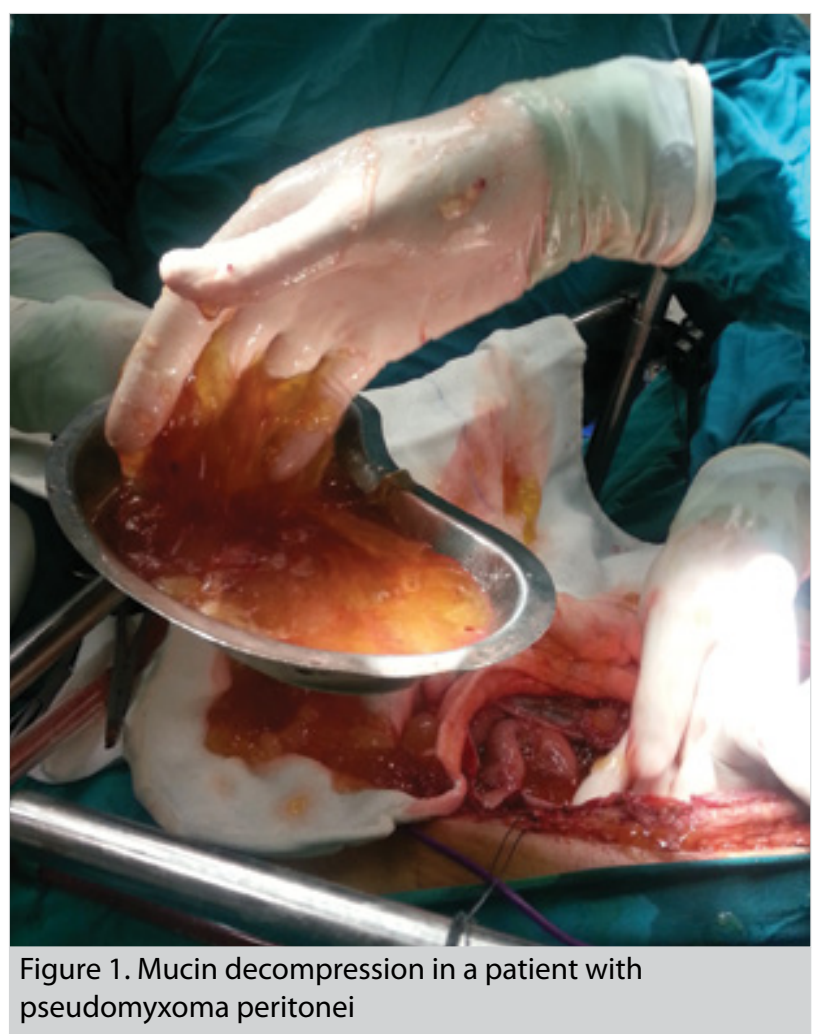


Peritoneal Carcinomatosis Index (PCl)

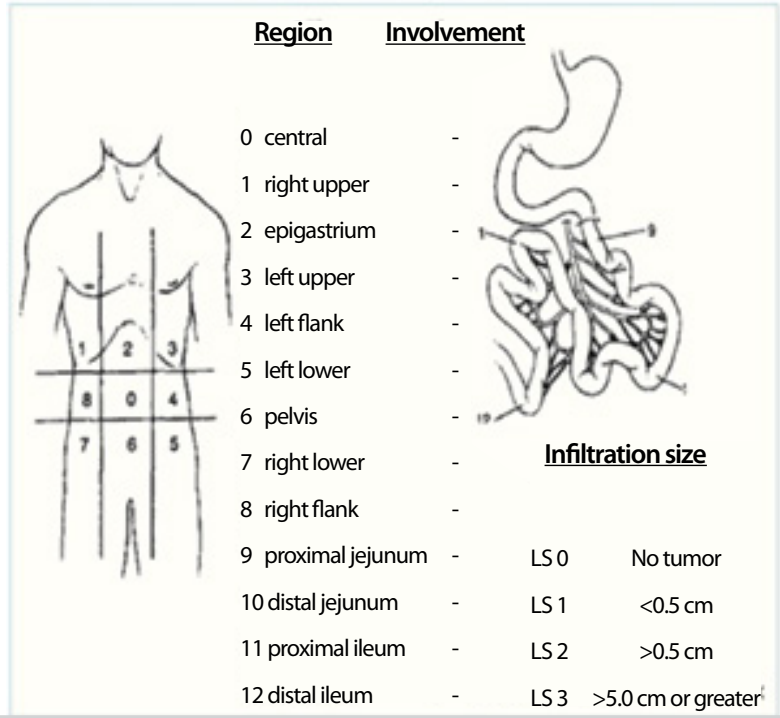

Peritoneal Surface Disease Severity Score (PSDSS)

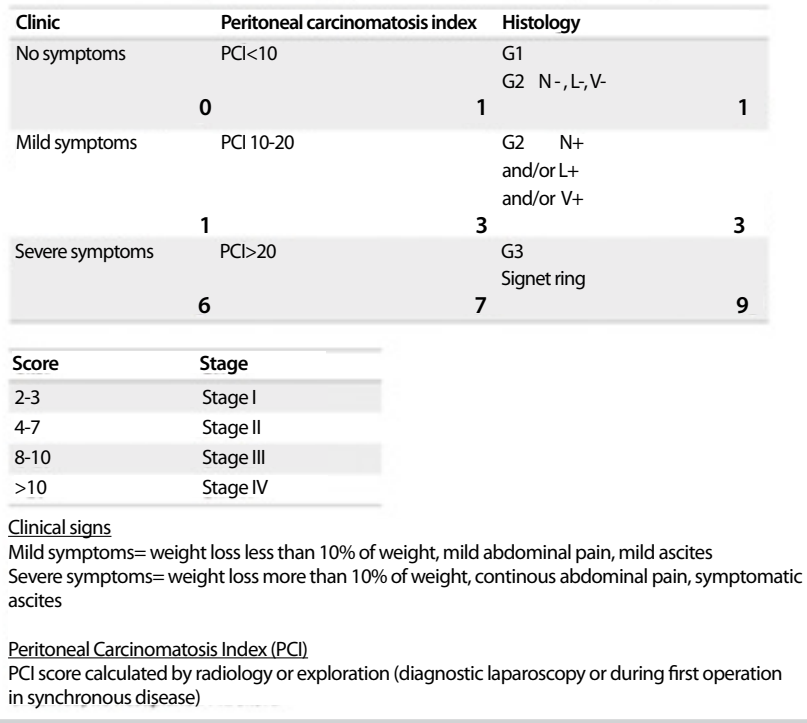

Figure 2. Scoring systems used in candidate patients for surgery. Peritoneal Carcinomatosis Index defined by Sugarbaker (12) and Peritoneal Surface Disease Severity Score defined by Esquivel (35)

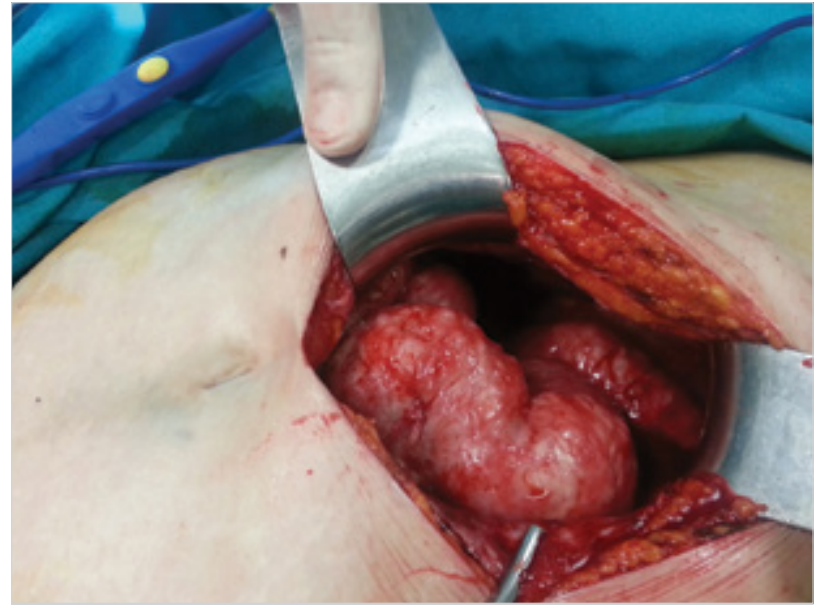

Figure 3. Intraoperative view of a patient judged as unresectable due to extensive small bowel involvement

in order to achieve complete penetration of the chemotherapy solution. Left diaphragmatic peritonectomy was performed in the same way; splenectomy was added in appropriate cases. Pelvic peritonectomy and pelvic organ resection (rectum, uterus and/or bladder) was performed en bloc with the extraperitoneal approach in patients requiring pelvic cytoreduction. During removal of the peritoneum covering the bladder as part of pelvic peritonectomy, the bladder was filled from the inside to prevent bladder injury. Injured or partially resected bladders were repaired. They were followed with urinary catheter for 7-15 days after surgery. In patients with ovary-related PC, bilateral pelvicpara-aortic lymph node dissection was routinely performed. Small nodular implants in the mesentery of the small intestine and the large intestine were removed or cauterized as the final step (Figure 6). Some cases required partial resection in order to remove the bulky small bowel mesentery involvement or had small defects in the intestinal wall. If a resection was performed at this stage, the anastomosis was left for after HIPEC application. Permanent intestinal repair was performed immediately in patients with small defects. In the visceral surfaces where tumor

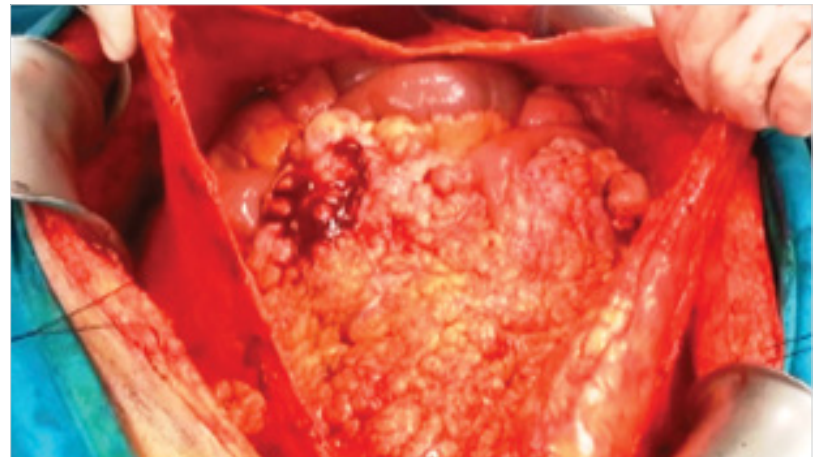

Figure 4. Parietal peritonectomy and omental cake in a patient who underwent total peritonectomy

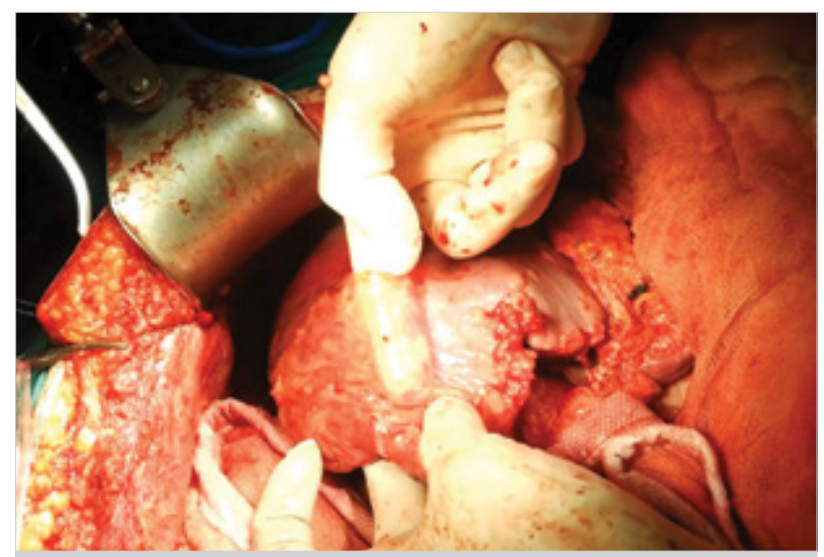

Figure 5. Removal of liver metastasis in the form of superficial invasion by stripping of Glisson capsule

tion was used. The completeness of cytoreduction was scored by using the residual tumor completeness scoring "Completeness of Cytoreduction" (CC) at the end of surgery (9). According to this scoring system no visible tumor remaining after surgery was considered as CCO, residual tumor size less than $2.5 \mathrm{~mm}$ as $\mathrm{CC} 1$, between 0.25 to $2.5 \mathrm{~cm}$ as $\mathrm{CC} 2$, and $\geq 2.5 \mathrm{~cm}$ is CC3. CCO and CC1 in ovarian PC and PMP, and CCO in CRC and stomach cancer were accepted as complete cytoreduction. In patients requiring anastomosis, the abdomen was temporarily closed and HIPEC 
was performed. Temporary closure of skin incision was achieved by continuous, interlocked $2 / 0$ sharp-bodied silk sutures. This liquid-tight closure method prevented overflow or leakage of chemotherapy solution during HIPEC. During HIPEC application, the abdomen was shaken with external manipulation to provide liquid access to all spaces and surfaces. All anastomoses were performed after HIPEC by re-opening the abdomen. In patients without requirement for anastomosis or with ostomy creation, the abdomen was permanently closed before HIPEC.

\section{Hyperthermic Intraperitoneal Chemotherapy}

Following cytoreduction, HIPEC was performed under general anesthesia with closed abdominal technique. Two inflow (deep pelvis and most affected area) and two outflow (superficial pelvis and subhepatic space) catheters were inserted into the abdomen, two temperature probes were placed and the skin was closed (Figure 7). Chemotherapeutics were added into 3-5 liters of perfusion solution according to the abdominal cavity volume, and intraperitoneal chemotherapy was administered at a constant temperature of $41-43^{\circ} \mathrm{C}$ in $60-90$ minutes by using HIPEC perfusion device. Cisplatin was used in 21 patients (75 $\left.\mathrm{mg} / \mathrm{m}^{2}\right)$, and oxaliplatin in $6\left(400 \mathrm{mg} / \mathrm{m}^{2}\right)$. The HIPEC solutions were prepared by the Oncology Department of our hospital, and were brought to the operating room by oncology nurses. Utmost attention was provided for staff safety during preparation of this solution and implementation in the operating room. Operating room personnel and technicians were trained in this regard. The patient's blood and biochemical parameters were evaluated in the middle of the HIPEC implementation period. Liver and renal functions were evaluated. Blood gases were routinely monitored assessing the needs of the patients and they were corrected accordingly. In patients with low serum albumin levels, human albumin replacement was done during the procedure. Red blood cell and fresh frozen plasma replacement was performed in operations longer than six hours, in high number of organ resections, and in patients with preoperative borderline values. At the end of HIPEC, anastomoses were performed by opening the skin and the abdomen was closed. Catheters placed for perfusion were left in place and were taken gradually in the postoperative period.

\section{Statistical Analysis}

The continuous variables were expressed as mean and distribution, and categorical variables as frequency and percentage. No statistical analysis or survival analysis was performed due to the limited number of patients.

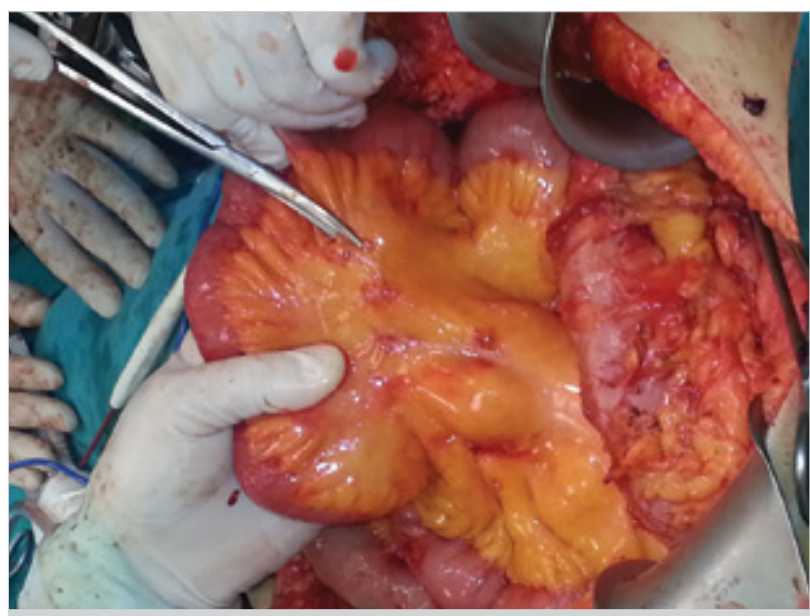

Figure 6. Excision of nodules within small bowel mesentery

\section{RESULTS}

Nineteen patients were female and eight were male. The mean age was 54 years (32-72). The primary tumor was CRC in 12 cases, ovarian cancer in 12, gasric cancer in 2, and PMP in one patient. Two patients (ovarian cancer) underwent neoadjuvant chemotherapy. In two of the patients with ovarian cancer, the surgery was a 'second look' approach. Mean PCI was 12 (3-32). The mean operative time (surgery and HIPEC) was 420 (300660) minutes. Peritonectomy in all quadrants was applied in 17 patients, three patients had pelvic peritonectomy (Figure 8) as well as right diaphragmatic peritonectomy (Figure 9), and two patients underwent a partial diaphragmatic peritonectomy. The diaphragm was injured during peritonectomy in three patients and primary repair was performed. None of these patients required a chest tube. The mean number of removed organs was 3.2 (1-7). Ten gastrointestinal anastomoses were performed on eight patients. The number of patients undergoing permanent stoma creation was four. The mean units of intraoperatively transfused red blood cells and fresh frozen plasma were 2 (1-5) and $1.2(1-2)$, respectively. The mean length of hospital stay was 10 (6-32) and ICU stay was 3 (1-18) days.

One of the patients with gastric cancer was a 36-year-old case with tumor recurrence (recurrence after 2.5 years of primary surgery for signet ring cell gastric cancer) who developed obstruction symptoms. The patient was evaluated as a candidate for this treatment based on preoperative $\mathrm{CT}$ and subsequent diagnostic laparoscopy findings. However, the findings during surgery were more aggressive than anticipated. Taking her age and good general condition into consideration total gastrectomy, pancreaticoduodenectomy, total colectomy, TAH + BSO and total peritonectomy were performed. However, the patient developed anastomotic leaks first from the ileorectal anastomosis, followed by esophagojejunostomy and biliary anastomotic leakage and died on the $22^{\text {nd }}$ day due to associated sepsis. Pelvic exenteration was performed in two cases with ovarian cancer. In a patient with third intraabdominal recurrence of colorectal cancer, a right nephrectomy and common bile duct resection were performed in addition to standard procedures. 10 months survival was obtained in this patient. Full cytoreduction (CCO) was achieved in the patient with pseudomyxoma peritonei with application of

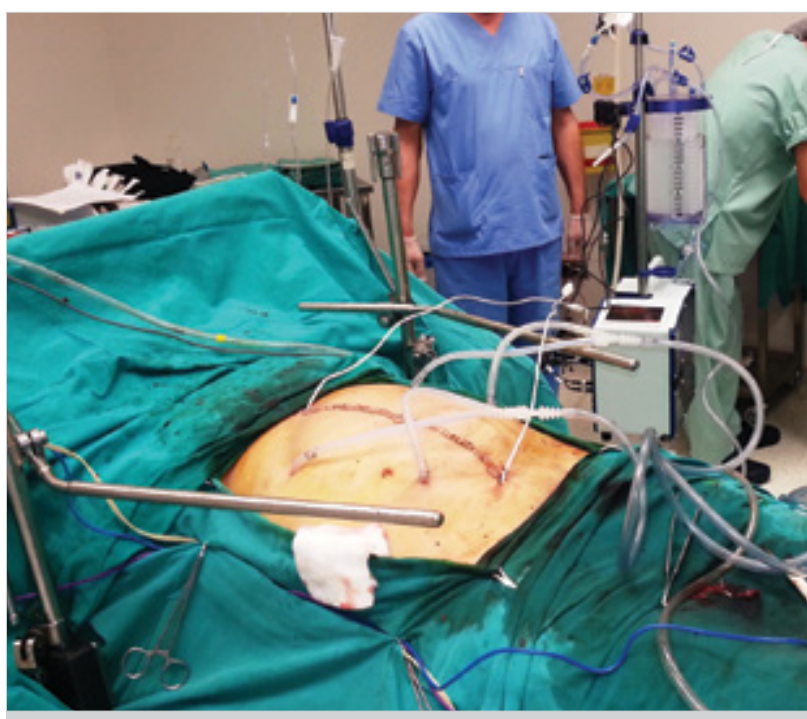

Figure 7. HIPEC application with closed abdominal technique (temporary closure of the abdomen leaving anastomoses for after HIPEC). Thin white cables are heat probes HIPEC: hyperthermic intraperitoneal chemotherapy 


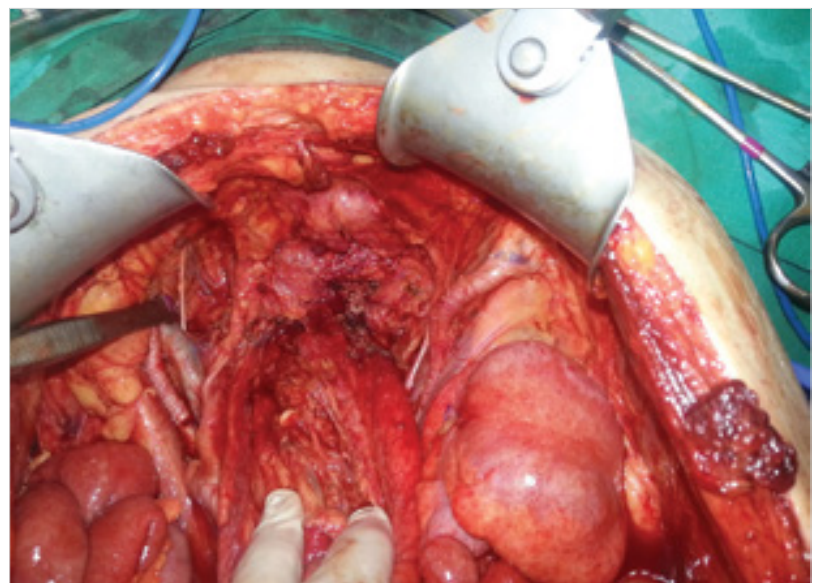

Figure 8. Obturator nerve and iliac vessels following pelvic peritonectomy and lymph node dissection

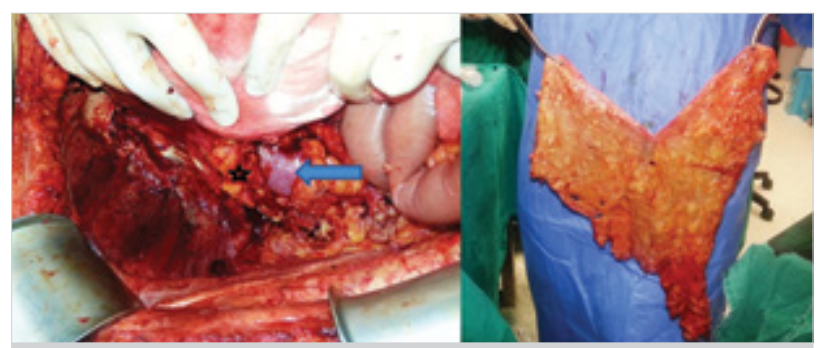

Figure 9. Completed right diaphragmatic peritonectomy, bare diaphragmatic fibers and excised specimen (blue arrow right kidney, black star right adrenal gland)

omentectomy, extended left hemicolectomy, low anterior resection, appendectomy, cholecystectomy, splenectomy, pancreatic capsule resection, removal of Falciform ligament and small omentum, metastasectomy of lesions in liver segments 4 and 6 , and total peritonectomy.

Perioperative morbidity was observed in $8(30 \%)$ patients. The main reasons were superficial surgical site infection, paralytic ileus, gastric paresis, anastomotic leak $(n=3)$, pulmonary embolism $(n=1)$, intra-abdominal sepsis and pleural effusion. HIPEC related toxicity was observed in 1 (3.7\%) patient (minimal hematologic toxicity, CTCAE 1). Perioperative mortality was seen in 4 (14.8\%) patients. Three patients had intra-abdominal sepsis, and the cause of death was abdominal hemorrhage in a patient. Intraabdominal sepsis was related to intestinal anastomotic leakage. A patient with colorectal cancer had sepsis secondary to left hepatic segment necrosis and leaks leading to mortality. This was thought to be related to the possible vascularization loss in these segments by ligation of an undetected replaced left hepatic artery during small omentum resection. Despite resection of necrotic liver, creation of an ileostomy with abdominal debridement and open abdomen follow-up, the patient died due to sepsis on the $22^{\text {nd }}$ postoperative day. Our patient who died due to bleeding, was operated for gastric cancer and died with a sudden, profuse bleeding on postoperative day 11 at the ward.

In a mean 13 (1-22) months follow-up, intra-abdominal recurrence was detected in two patients with CRC after 9 months (patient who underwent nephrectomy and resection of the common bile duct) and 12 months, and one patient with ovarian cancer at 11 months. In two of these patients, the PCl was above 20 and complete cytoreduction could not been reached. at the $13^{\text {th }}$ postoperative month, which was treated with resection of segments 6-7. This patient is still alive. Other patients are still being monitored, disease-free. All 23 patients without perioperative mortality were treated with adjuvant chemotherapy. The survival rate was $95.8 \%$, and the disease-free survival rate was $82.6 \%$ in 13 -months follow-up.

\section{DISCUSSION}

Large series (14-18) and randomized studies (19-23) published in recent years show that curative approach to PC may prolong survival in selected patients. Based on these results, radical surgery and intraperitoneal chemotherapy are being increasingly applied as a treatment option for PC. A limited number of centers (24) perform this procedure in our country, and it is being carried out at our center since 2012. The small number of patients, the short follow-up period and lack of survival analysis are the limitations of our study. The early results of our series of consecutive patients who underwent surgery at a single center are consistent with the literature and therefore encouraging.

Requirement for multiple organ resections, the longer operation time and intraperitoneal chemotherapy as well as having received neoadjuvant chemotherapy, previous abdominal surgeries and having low performance scores make PC patients a high-risk group for complications. The overall morbidity after CRS and HIPEC is reported as $12-56 \%$ and perioperative mortality between $0-12 \%$, in the literature, (25-28). The morbidity rate is associated with disease dissemination, cytoreduction extension, number of removed organs, age, perioperative blood loss and operative time $(29,30)$. Another effective factor on complication rates is reported as the learning curve ( $>200$ procedures) and center experience (31), although there is acceptable mortality and morbidity rates published from medium volume centers (32). HIPEC-related toxicity is the most important cause of morbidity and mortality in these patients. HIPEC drugs and doses must be chosen based on thorough preoperative evaluation of kidney and bone marrow functions, and the patient should be closely monitored in the early postoperative period in terms of renal and hematological toxicity as well as long-term hematologic toxicity (26). In our series, half of the complications occurring in eight patients (15\%) were severe (grade 3-5) complications. The patient who underwent extensive cytoreduction with pancreaticoduodenectomy and low anterior resection for recurrent gastric cancer developed leakage from the esophagojejunostomy and rectal anastomosis resulting in perioperative mortality. During this patient's exploration, the PCl was determined as 22, and a decision for aggressive surgery was taken based on her young age and good performance status. Morbidity is almost inevitable in this major surgical approach for reasons mentioned above. The morbidity rate of our series is consistent with the literature. However, our mortality rate is higher. We believe that the center's lack of experience and selection of questionable patients played a role in this result. In a study of 100 patients, Moran et al. (33) reported a mortality rate of $18 \%$ in the first 33 cases, $3 \%$ in the second 33 patients, and $3 \%$ in the last 33 patients. They emphasized that the mortality rate decreases with increasing experience, and that all involved teams should gain experience.

Disease dissemination and extent of the procedures required to achieve complete cytoreduction are the most important prognostic factors on both perioperative surgical outcomes (mortality and morbidity) and long-term oncologic outcomes (9). Selection of patients who are candidates for curative treatment is a difficult decision that requires assessment of many factors related to 
the patient and the tumor in combination. Piso et al. (34) listed factors influencing the decision for curative approach as follows: Tumor-related factors; tumor origin, histological grade, presence of metastatic disease, para-aortic lymph node involvement, $\mathrm{PCI}$, small bowel involvement, hepatogastric ligament involvement, biliary/urinary obstruction and the response to previous chemotherapies. Other factors included patient performance status, comorbidity, learning curve, informed consent, predicted postoperative quality of life and the multidisciplinary council decision. Diagnostic laparoscopy and PET/CT are other useful tools used in patient selection. Within these parameters, the completeness of cytoreduction, tumor volume (PCl) and histological grade were emphasized as the most important independent prognostic factors for complications and survival in various studies. Intraoperative staging and identification of $\mathrm{PCl}$ as defined by Sugarbaker are the most common methods used to predict full cytoreduction (Figure 2) (12). The Peritoneal Surface Disease Severity Score (PSDSS) defined by Esquivel (35) is a more comprehensive system including clinical, radiologic and histological parameters. In this system, patient's symptoms (weight loss, ascites, abdominal pain, obstruction), radiologic $\mathrm{PCl}$ and primary histopathological features of the tumor (tumor grade, lymph node involvement, lymphatic/venous invasion, signet ring cell histology) are given scores, and the disease is classified into four stages (Figure 2). This staging has been shown to be associated with long-term oncologic results of patients with CRC and PMP treated with CRS and HIPEC, and it has been accepted as a reliable method in the selection of the patients that would benefit from treatment $(35,36)$.

Computed tomography and PET/CT are used in the diagnosis and staging of peritoneal carcinomatosis, as in our series. However, preoperative radiologic findings may be inadequate in patient selection (37). We believe that diagnostic laparoscopy is of great importance in these patients to detect inoperability and decide on treatment strategies. In our series, we used diagnostic laparoscopy in five patients. One of these patients had gastric cancer, one PMP, and the other three had ovarian cancer. While two patients were secondary cases, the other three were primary patients. In patients with primary ovarian cancer, diagnosis was verified by biopsy while also performing ascites decompression. It was decided to proceed with neoadjuvant chemotherapy followed by CRS and HIPEC. The patient with gastric cancer was selected for CRS and HIPEC based on diagnostic laparoscopy findings. The other secondary ovarian tumor was also directed to CRS and HIPEC treatment. PMP patients were treated directly with CRS and HIPEC. Laparoscopy is recently being used for CRS and HIPEC for both preoperative evaluation and as a direct surgical technique. It is a valuable technique that can show the presence of peritoneal carcinomatosis or if the disease is inoperable / unresectable before cytoreductive surgery (38). Nevertheless, it should be kept in mind that this method may lead to under/overstaging of the disease (39). In patients undergoing laparoscopy, the retroperitoneum, mesenteric root, pancreatic invasion must be thoroughly evaluated with preoperative CT. Diagnostic laparoscopy is especially helpful in the evaluation of military small bowel serosal involvement that is overlooked in PET CT and CT. The algorithm used in our center for patient selection and treatment is shown in Figure 10.

Peritoneal carcinomatosis can be detected in $5-30 \%$ of patients who underwent potentially curative surgery for gastric cancer, and the median survival in these patients is reported as $1-3$ months with systemic chemotherapy $(40,41)$. The role of CRS and HIPEC in gastric cancer remains controversial. In 2010, Glehn et al. (42) reported the median survival as 9.2 months and 5 -year overall survival as $13 \%$ in 150 patients from 15 centers treated with CRS and HIPEC. Yang et al. (43) performed the first randomized phase III clinical study, and the median survival in 68 patients with CRS and HIPEC was reported as 11 months, and as 13.5 months if complete cytoreduction was reached. The group receiving only CRS had a significantly shorter median survival of 6.5 months. In another study, results of 441 patients with CRS and HIPEC were compiled revealing a median survival of 7 months, reporting 11 months of survival in patients with complete cytoreduction (40). The most important prognostic data in the literature on gastric cancer related PC is reported as complete cytoreduction. In our series, although complete cytoreduction was achieved in two patients with gastric cancer, patients were lost due to surgical complications.

There are a number of studies showing the positive impact of CRS and HIPEC on oncologic outcomes of patients with CRC, approximately $10 \%$ of which present with $P C$ at the time of diagnosis (Table 1) $(15,17,19,20,44-47)$. Despite numerous

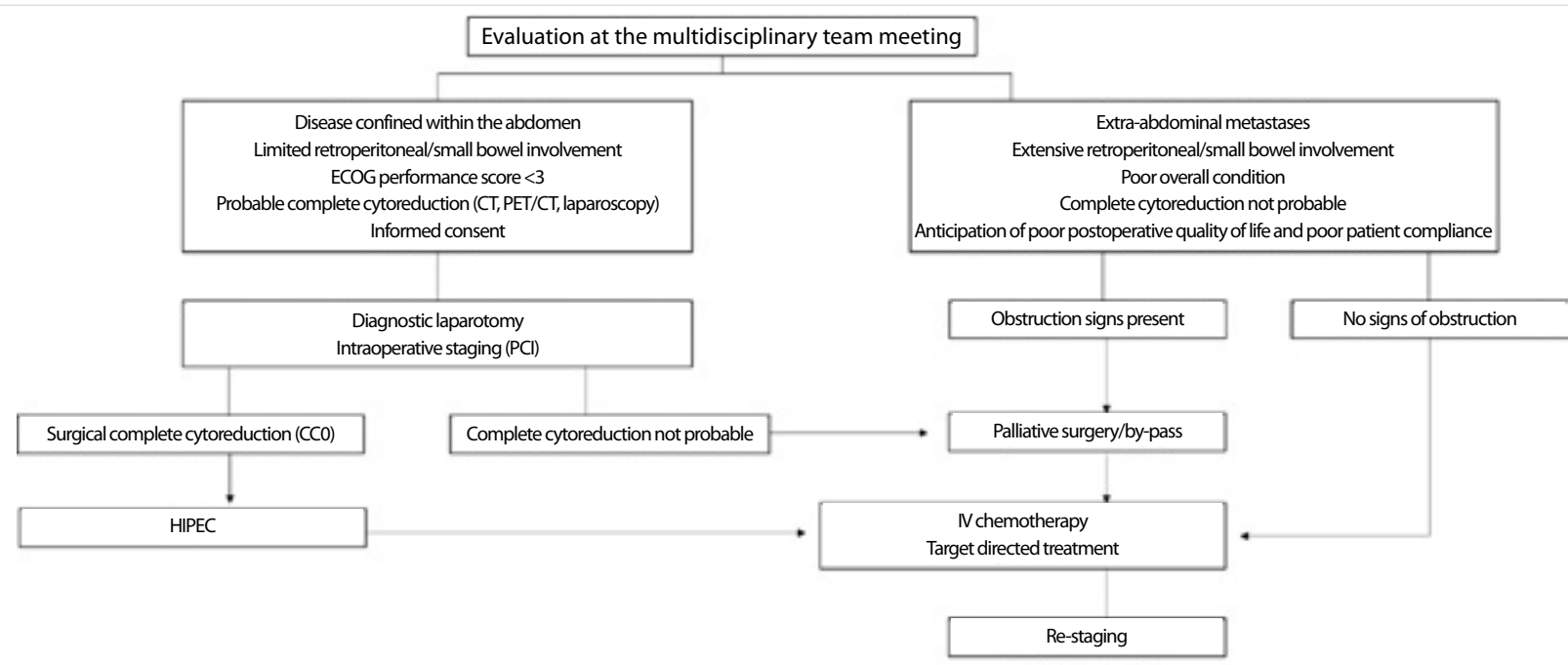

Figure 10. The algorithm used in our center in the approach of patients with peritoneal carcinomatosis HIPEC: hyperthermic intraperitoneal chemotherapy; ECOG: ECOG performance status; CT: computed tomography; PET/CT: positron emission tomography/computed tomography 
innovations such as targeted therapy, the results of systemic chemotherapy alone are still worse than that of CRS and HIPEC (48). Full-cytoreduction and $\mathrm{PCl}$ scores are the most powerful prognostic factors for survival. Complete cytoreduction can only be achieved in $80 \%$ of patients (49). CRS and HIPEC do not increase survival in CRC acquired PC if complete cytoreduction could not be achieved (20). Therefore, the role of HIPEC in patients where R0 resection cannot be reached is controversial. On the other hand, numerous studies that compared CRS alone vs. CRS + HIPEC demonstrated a positive impact with HIPEC application $(45,49)$. Terzi et al. (50) described a generally accepted algorithm for the treatment approach of patients with CRC derived PC. According to this algorithm, patients without extra-abdominal metastases, good general condition, with limited small intestine involvement are accepted as candidates for exploratory laparotomy, and HIPEC is recommended following surgery in patients with complete cytoreduction. In our series, two patients who developed recurrence had $\mathrm{PCl}$ scores higher than 20. Both patients had a CC1 cytoreduction score. The remaining of our patients are still alive. The generally accepted contraindications for CRS and HIPEC in colorectal cancer related PC patients are poor general condition, presence of extra-abdominal metastases and more than 3 liver metastases (51).

The mean survival of patients with ovarian cancer related PC with conventional treatment is $12-25$ months (52). The positive results of the studies suggest application of intraperitoneal chemothera- py in ovarian cancer patients with complete cytoreduction, and it is considered as the standard approach for stage III ovarian cancer (53). Studies on the role of CRS and HIPEC in patients with ovarian cancer are not randomized controlled trials. However, many observational studies on large series reported 22-64 month median survival and 12-66\% 5-year overall survival with CRS and HIPEC, and it is emphasized that the biggest benefit of treatment is seen in patients with complete cytoreduction (54).

Table 2 presents important studies on the results of CRS and HIPEC in ovarian origin PC (55-62). In our center, we treated 12 patients with stage III ovarian cancer with CRS and HIPEC, achieved CCO in 10, and complete cytoreduction with CC1 in two cases. Two patients with ovarian cancer had recurrences during follow-up. One patient had a recurrence at 11 months (diffuse intra-abdominal involvement), and the other at 13 months (liver metastases). The first patient received systemic chemotherapy, while the second was treated with surgery and underwent resection of liver segments 6 and 7. This patient is disease-free at 6 months following the second surgery.

Pseudomyxoma peritonei is the group with the best prognosis within peritoneal surface malignancies, and lately 10-year survival rates are being mentioned for this group after CRS and HIPEC. In a multicenter study on 2296 patients treated with CRS and HIPEC, the median survival has been reported as 196 months, and 10year overall survival rate as $63 \%$ (63). In the same study, the mean

Table 1. Results of large series on cytoreductive surgery and intraperitoneal chemotherapy for colorectal cancer

\begin{tabular}{|llccccc}
\hline Author, Center, Year & $\begin{array}{c}\text { Study } \\
\text { design }\end{array}$ & $\begin{array}{c}\text { Patient } \\
\text { number }\end{array}$ & $\begin{array}{c}\text { Complete } \\
\text { CRS (\%) }\end{array}$ & $\begin{array}{c}\text { Intraperitoneal } \\
\text { chemotherapy }\end{array}$ & $\begin{array}{c}\text { Median } \\
\text { follow-up (months) }\end{array}$ & $\begin{array}{c}\text { Median } \\
\text { survival (months) }\end{array}$ \\
\hline Verwaal, Amsterdam, 2003 (44) & Randomized & 105 & $*$ & HIPEC & 21.6 & 22.3 \\
\hline Glehen, multi-center, 2004 (19) & Retrospective & 506 & 53.5 & HIPEC/EPIC & 53 & 19.2 \\
\hline Da Silva, Washington, 2006 (17) & Retrospective & 70 & 100 & HIPEC/EPIC & 46.5 & 33 \\
\hline Levine, Wake Forest, 2007 (15) & Retrospective & 133 & $*$ & HIPEC & 55.4 & 16.4 \\
\hline Shen, Wake Forest, 2008 (46) & Retrospective & 121 & 45 & HIPEC & 86 & 34 \\
\hline Elias, France, 2009 (45) & Retrospective & 48 & $*$ & HIPEC & 63 & 62.7 \\
\hline Elias, France, 2010 (20) & Retrospective & 523 & 84 & HIPEC/EPIC & 45 & 30.1 \\
\hline Quenet, France, 2011 (47) & Retrospective & 146 & 90 & HIPEC & 48.5 & 41
\end{tabular}

CRS: cytoreductive surgery; HIPEC: hyperthermic intraperitoneal chemotherapy; EPIC: early postoperative chemotherapy; *not reported

Table 2. Results of some series on cytoreductive surgery and hyperthermic intraperitoneal chemotherapy for ovarian cancer related peritoneal carcinomatosis

\begin{tabular}{|llcccc|}
\hline Author, Center, Year & $\begin{array}{c}\text { Study } \\
\text { design }\end{array}$ & $\begin{array}{c}\text { Patient } \\
\text { number }\end{array}$ & $\begin{array}{c}\text { Complete } \\
\text { CRS (\%) }\end{array}$ & $\begin{array}{c}\text { Median } \\
\text { follow-up (months) }\end{array}$ & $\begin{array}{c}\text { Median survival } \\
\text { (months) }\end{array}$ \\
\hline Ryu, Seul, 2004 (55) & Retrospective & 57 & 84 & 47 & $49^{* *}$ \\
\hline Cotte, France, 2007 (56) & Retrospective & 81 & 56 & 47 & 28 \\
\hline Guardiola, France, 2009 (57) & Retrospective & 47 & $*$ & 23 & $14^{* *}$ \\
\hline Pavlov, Belgrade, 2009 (58) & Retrospective & 56 & 93 & 60 & 38 \\
\hline Helm, multi-center USA, 2010 (59) & Retrospective & 83 & 58 & 18 & 30 \\
\hline Parson, Wake Forest, 2011 (60) & Retrospective & 51 & 40 & 98 & 29 \\
\hline Deraco, Milan, 2011 (61) & Retrospective & 26 & 58 & 25 & $30^{* *}$ \\
\hline Bakrin, France, 2013 (62) & Retrospective & 473 & 75 & 40 & $35-45^{* * *}$ \\
\hline
\end{tabular}

CRS: cytoreductive surgery; HIPEC: hyperthermic intraperitoneal chemotherapy; EPIC: early postoperative chemotherapy; ${ }^{*}$ ot reported, ${ }^{* *}$ disease-free survival, ***ocally advanced-recurrent patients 
$\mathrm{PCl}$ was 20 and the rate of achieving complete cytoreduction was $83 \%$. Independent negative prognostic factors for overall survival has been shown as a history of adjuvant chemotherapy, major complications, CC2/CC3 cytoreduction, CRS without HIPEC, high $\mathrm{PCl}$ score and age. In this particular group of patients, $\mathrm{PCl}$ and not achieving $\mathrm{R} 0$ resection do not constitute contraindications for HIPEC, and in contrast to other gastrointestinal origin PCs, it is recommended that all peritoneal surfaces be removed even if they are not affected by the disease (64). Pseudomyxoma peritonei is the disease with the best response to this treatment regardless of the $\mathrm{PCl}$ score. In our series, the $\mathrm{PCl}$ score of the only PMP patient was 32 on intraoperative staging and the patient is still being followed-up disease free at 21 months after cytoreductive surgery and HIPEC.

Many chemotherapy drugs were evaluated in this treatment method. These include various medications varying from one center to another such as cisplatin, mitomycin C, paclitaxel, liposomal doxorubicin, oxaliplatin, carboplatin, docetaxel and irinotecan that have particularly increased activities at high temperature (65). The common chemotherapeutic drug used in HIPEC for colorectal cancer, ovarian cancer and primary peritoneal tumors is cisplatin. Cisplatin is the drug with the most common experience based on clinical trials (66). In our study, the most commonly used drug was also cisplatin. Oxaliplatin was the second most commonly used drug. Currently, cisplatin and mitomycin- $\mathrm{C}$ are the most commonly used drugs alone or in combination in ovarian cancer related PC, cisplatin, mitomycin- $\mathrm{C}$ and oxaliplatin in $\mathrm{CRC}$, mitomycin-C in PMP, and cisplatin and mitomycin- $C$ in gastric cancer (65). Recent publications indicate that oxaliplatin alone offer similar results with fewer side effects than combinations in CRC related PC (67). Nowadays not only chemotherapeutic agents but also biological treatment is considered for HIPEC. Studies on trifunctional antibody catumaxomab are especially promising (68). Studies examining the role of bevacizumab, which is another commonly used angiogenesis inhibitor monoclonal antibody, in HIPEC treatment continue with promising results (69). An increase in the efficiency of HIPEC along with a decrease in secondary morbidity is expected with new drugs and studies, more effective patient choice and better perioperative management.

The most toxic drug within the commonly used therapeutic agents is known as cisplatin. Nausea, vomiting and renal toxicity are its significant side effects. Certain measures should be taken against these side effects before and during application of HIPEC (70). Paclitaxel related myelosuppression and neurotoxicity, oxaliplatin-induced neurotoxicity, and increase in the risk of infection secondary to any drug are important (71). In our study, there were no toxic side effects other than minimal bone marrow depression in one patient. It is difficult to decide if nausea, vomiting, gastric paresis, and temporary ileus are related to the extensive radical surgery or the chemotherapeutic drugs. Therefore, such clinical conditions were evaluated in the concept of overall morbidity.

Colorectal cancer and HIPEC are considered as the only curative treatment options in PC, based on developments in the last two decades and published positive results. There are several ongoing randomized controlled trials on treatment outcomes, while studies have recently focused on detection of patients at risk for development of peritoneal metastasis, and proactive management with prophylactic HIPEC application and/or 'second look' surgery. The role of prophylactic HIPEC in gastric cancer patients without peritoneal metastasis has been demonstrated in numerous studies and meta-analysis (72-74). Elias et al. (75) advised surgical exploration in CRC patients at high-risk for PC after 6 months of adjuvant systemic chemotherapy. The proactive risk management proposed by Sugarbaker includes close monitoring and "second look" surgery when required in patients who are at high-risk of local recurrence and PC, such as tumor perforation, T4 tumors, and obstruction. It is an algorithm based on physical examination, close monitoring with CEA and CT (76). According to this algorithm, re-operative surgery is planned whenever a finding suspicious for recurrence, such as elevation in CEA levels, is detected without further delay. All high-risk patients are evaluated at the end of the first year with planned "second look" operations, regardless of clinical suspicion. Patients with local recurrence or PC on "second look" surgery are treated by the principles mentioned above, and those without any findings undergo omentectomy, oophorectomy and HIPEC application. Prophylactic HIPEC and 'second look' approach are recommended for high-risk patients with ovarian, gastric and CRC (77). There is a need for randomized controlled trials on the subject. In our series, two patients with ovarian cancer were assessed by laparotomy after receiving adjuvant chemotherapy following the initial surgery, and were treated with CRS and HIPEC upon detection of PC.

\section{CONCLUSION}

Cytoreductive surgery and HIPEC improve survival in patients with PC. Full-cytoreduction is the most important criterion to obtain the maximum benefit from this approach. Curative approach is not indicated in all patients with PC. Good patient condition, absence of extra-abdominal metastases, being able to achieve $\mathrm{R} 0$ or at worst $\mathrm{R} 1$ resection as determined by peritoneal disease volume (tumor burden) and application of HIPEC in patients with full CRS are the generally accepted indications in the current literature. Appropriate patient selection and center expertise are important factors that affect surgical results and survival rates.

Ethics Committee Approval: Since it is a retrospective study, we did not apply for ethical committee approval and obtained our data from patients'files.

Informed Consent: Written informed consent was obtained from patients who participated in this study.

Peer-review: Externally peer-reviewed.

Author Contributions: Concept - K.T.; Design - K.T., N.Ç.A.; Supervision - K.T., M.B.Ç, M.K.G., Z.M.; Materials - N.Ç.A., M.Ç.; Data Collection and/ or Processing - M.K.G., M.Ç., M.F.G.; Analysis and/or Interpretation - K.T., N.Ç.A., M.K.G., Z.M.; Literature Review - K.T., N.Ç.A., D.E.;Writer - K.T.; Critical Review - K.T., Z.M., M.B.Ç., N.Ç.A.; Other - D.E., M.F.G.

Conflict of Interest: No conflict of interest was declared by the authors.

Financial Disclosure: The authors declared that this study has received no financial support.

\section{REFERENCES}

1. Spratt JS, Adcock RA, Sherrill W, Travathen S. Hyperthermic peritoneal perfusion system in canines. Cancer Res 1980; 40: 253-255.

2. Spratt JS, Adcock RA, Muskovin M, Sherrill W, McKeown J. Clinical delivery system for intraperitoneal hyperthermic chemotherapy. Cancer Res 1980; 40: 256-260.

3. Chu DZ, Lang NP, Thompson C, Osteen PK, Westbrook KC. Peritoneal carcinomatosis in nongynecologic malignancy. A prospective study of prognostic factors. Cancer 1989; 63: 364-367. [CrossRef]

4. Jayne D, Fook S, Seow-Choen F. Peritoneal carcinomatosis from colorectal cancer. Br J Surg 2002; 89: 1545-1550. [CrossRef] 
5. Sugarbaker PH, Gianola FJ, Speyer JL Wesley R, Barofsky I, Meyers CE. Prospective randomized trial of intravenous vs intraperitoneal 5-FU in patients with advanced primary colon or rectal cancer. Semin Oncol 1985; 12: 101-111.

6. Markman M. Intraperitoneal chemotherapy in the management of malignant disease. Expert Rev Anticancer Ther 2001; 1: 142-148. [CrossRef]

7. Kampinga HH, Dynlacht JR, Dikomey E. Mechanism of radiosensitization by hyperthermia ( $>$ or $=43$ degrees $C$ ) as derived from studies with DNA repair defective mutant cell lines. Int J Hyperthermia 2004; 20: 131-139. [CrossRef]

8. Issels RD. Hyperthermia adds to chemotherapy. Eur J Cancer 2008; 44: 2546-2554. [CrossRef]

9. Esquivel J, Elias D, Baratti D, Kusamura S, Deraco M. Consensus statement on the loco regional treatment of colorectal cancer with peritoneal dissemination. J Surg Oncol 2008; 98: 263-267. [CrossRef]

10. Dindo D, Demartines N, Clavien PA. Classification of surgical complications: a new proposal with evaluation in a cohort of 6336 patients and results of a survey. Ann Surg 2004; 240: 205-213. [CrossRef]

11. National Cancer Institute (NCI)/National Institute of Health (NIH). Common Terminology Criteria for Adverse Events (CTCAE), version 3.0. https://webapps.ctep.nci.nih.gov/webobjs/ctc/webhelp/welcome_to_ctcae.htm [accessed 30 April 2012].

12. Jacquet $P$, Sugarbaker PH. Current methodologies for clinical assessment of patients with peritoneal carcinomatosis. J Exp Clin Cancer Res 1996; 15: 49-58.

13. An overview of peritonectomy. Visceral Resections, and Perioperative Chemotherapy for Peritoneal Surface Malignancy. "Cytoreductive Surgery \& Perioperative Chemotherapy for Peritoneal Surface Malignancy, textbook and Video Atlas, Ed. Paul H. Sugarbaker, Cine-Med Publishing, Inc. 2013.p.1-30.

14. Shen P, Hawksworth J, Lovato J, Loggie BW, Geisinger KR, Fleming $R A$, et al. Cytoreductive surgery and intraperitoneal hyperthermic chemotherapy with mitomycin C for peritoneal carcinomatosis from nonappendiceal colorectal carcinoma. Ann Surg Oncol 2004; 11: 178-186. [CrossRef]

15. Levine EA, Stewart JH, Russell GB, Geisinger KR, Loggie BL, Shen P. Cytoreductive surgery and intraperitoneal hyperthermic chemotherapy for peritoneal surface malignancy: experience with 501 procedures. J Am Coll Surg 2007; 204: 943-945. [CrossRef]

16. Verwaal VJ, van Ruth S, Witkamp A, Boot H, van Slooten G, Zoetmulder FA. Longterm survival of peritoneal carcinomatosis of colorectal origin. Ann Surg Oncol 2005; 12: 65-71. [CrossRef]

17. Da Silva RG, Sugarbaker PH. Analysis of prognostic factors in seventy patients having a complete cytoreduction plus perioperative intraperitoneal chemotherapy for carcinomatosis from colorectal cancer. J Am Coll Surg 2006; 203: 878-886. [CrossRef]

18. Yan TD, Morris DL. Cytoreductive surgery and perioperative intraperitoneal chemotherapy for isolated colorectal peritoneal carcinomatosis: experimental therapy or standard of care? Ann Surg 2008; 248 : 829-835.

19. Glehen O, Kwiatkowski F, Sugarbaker PH, Elias D, Levine EA, De Simone $M$, et al. Cytoreductive surgery combined with perioperative intraperitoneal chemotherapy for the management of peritoneal carcinomatosis from colorectal cancer: a multiinstitutional study. J Clin Oncol 2004; 22: 3284-3292. [CrossRef]

20. Elias D, Gilly F, Boutitie F, Quenet F, Bereder JM, Mansvelt B, et al. Peritoneal colorectal carcinomatosis treated with surgery and perioperative intraperitoneal chemotherapy: retrospective analysis of 523 patients from a multicentric French study. J Clin Oncol 2010; 28: 63-68. [CrossRef]

21. Chua TC, Morris DL, Esquivel J. Impact of the peritoneal surface disease severity score on survival in patients with colorectal cancer peritoneal carcinomatosis undergoing complete cytoreduction and hyperthermic intraperitoneal chemotherapy. Ann Surg Oncol 2010; 17: 1330-1336. [CrossRef]

22. Cavaliere F, De Simone M, Virzì S, Deraco M, Rossi CR, Garofalo A, et al. Prognostic factors and oncologic outcome in 146 patients with colorectal peritoneal carcinomatosis treated with cytoreductive surgery combined with hyperthermic intraperitoneal chemotherapy: Italian multicenter study S.I.T.IL.O. Eur J Surg Oncol 2011; 37: 148154. [CrossRef]

23. Glehen O, Gilly FN, Boutitie F, Bereder JM, Quenet F, Sideris L, et al. French Surgical Association. Toward curative treatment of peritone- al carcinomatosis from nonovarian origin by cytoreductive surgery combined with perioperative intraperitoneal chemotherapy: a multiinstitutional study of 1,290 patients. Cancer 2010; 116: 5608-5618. [CrossRef]

24. Füzün M, Sökmen S, Terzi C, Canda AE. Cytoreductive approach to peritoneal carcinomatosis originated from colorectal cancer:Turkish experience. Acta Chir lugosl 2006; 53: 17-21. [CrossRef]

25. Di Miceli D, Alfieri S, Caprino P, Menghi R, Quero G, Cina C, et al. Complications related to hyperthermia during hyperthermic intraoperative intraperitoneal chemotherapy (HIPEC) treatment. Do they exist? Eur Rev Med Pharmacol Sci 2012; 16: 737-742.

26. Canda AE, Sokmen S, Terzi C, Arslan C, Oztop I, Karabulut B, et al. Complications and toxicities after cytoreductive surgery and hyperthermic intraperitoneal chemotherapy. Ann Surg Oncol 2013; 20: 1082-1087. [CrossRef]

27. Roviello F, Marrelli D, Neri A, Cerretani D, de Manzoni G, Pedrazzani $\mathrm{C}$, et al. Treatment of peritoneal carcinomatosis by cytoreductive surgery and intraperitoneal hyperthermic chemoperfusion (IHCP): Postoperative outcome and risk factors for morbidity. World J Surg 2006; 30: 2033-2040. [CrossRef]

28. Chua TC, Yan TD, Saxena A, Morris DL. Should the treatment of peritoneal carcinomatosis by cytoreductive surgery and hyperthermic intraperitoneal chemotherapy still be regarded as a highly morbid procedure?: A systematic review of morbidity and mortality. Ann Surg 2009; 249: 900-907. [CrossRef]

29. Kusamura S, Younan R, Baratti D, Costanzo P, Favaro M, Gavazzi C, et al. Cytoreductive surgery followed by intraperitoneal hyperthermic perfusion: analysis of morbidity and mortality in 209 peritoneal surface malignancies treated with closed abdomen technique. Cancer 2006; 106: 1144-1153. [CrossRef]

30. Glehen O, Osinsky D, Cotte E, Kwiatkowski F, Freyer G, Isaac S, et al. Intraperitoneal chemohyperthermia using a closed abdominal procedure and cytoreductive surgery for the treatment of peritoneal carcinomatosis: morbidity and mortality analysis of 216 consecutive procedures. Ann Surg Oncol 2003; 10: 863-869. [CrossRef]

31. Andréasson H, Lorant T, Påhlman L, Graf W, Mahteme H. Cytoreductive surgery plus perioperative intraperitoneal chemotherapy in pseudomyxoma peritonei: aspects of the learning curve. Eur I Surg Oncol 2014; 40: 930-936. [CrossRef]

32. Kerscher AG, Mallalieu J, Pitroff A, Kerscher F, Esquivel J. Morbidity and mortality of 109 consecutive cytoreductive procedures with hyperthermic intraperitoneal chemotherapy (HIPEC) performed at a community hospital. World J Surg 2010; 34: 62-69. [CrossRef]

33. Moran BJ. Decision-making and technical factors account for the learning curve in complex surgery. J Public Health (Oxf) 2006; 28 : 375-378. [CrossRef]

34. Piso P, Glockzin G, von Breitenbuch P, Sulaiman T, Popp F, Dahlke M, et al. Patient selection for a curative approach to carcinomatosis. Cancer J 2009; 15: 236-242. [CrossRef]

35. Esquivel J, Lowy AM, Markman M, Chua T, Pelz J, Baratti D, et al. The American Society of Peritoneal Surface Malignancies (ASPSM) multiinstitution evaluation of the Peritoneal Surface Disease Severity Score (PSDSS) in 1,013 patients with colorectal cancer with peritoneal carcinomatosis. Ann Surg Oncol 2014; 21: 4195-4201. [CrossRef]

36. Esquivel J, Garcia SS, Hicken W, Seibel J, Shekitka K, Trout R. Evaluation of a new staging classification and a Peritoneal Surface Disease Severity Score (PSDSS) in 229 patients with mucinous appendiceal neoplasms with or without peritoneal dissemination. J Surg Oncol 2014; 110: 656-660. [CrossRef]

37. Esquivel J, Chua TC, Stojadinovic A, Melero JT, Levine EA, Gutman M, et al. Accuracy and clinical relevance of computed tomography scan interpretation of peritoneal cancer index in colorectal cancer peritoneal carcinomatosis: a multi-institutional study. J Surg Oncol 2010; 102: 565-570. [CrossRef]

38. Jayakrishnan TT, Zacharias AJ, Sharma A, Pappas SG, Gamblin TC, Turaga KK. Role of laparoscopy in patients with peritoneal metastases considered for cytoreductive surgery and hyperthermic intraperitoneal chemotherapy (HIPEC). World J Surg Oncol 2014; 21: 270. [CrossRef]

39. Iversen LH, Rasmussen PC, Laurberg S. Value of laparoscopy before cytoreductive surgery and hyperthermic intraperitoneal chemotherapy for peritoneal carcinomatosis. Br J Surg 2013; 100: 285-292. [CrossRef]

40. Gill RS, Al-Adra DP, Nagendran J, Campbell S, Shi X, Haase E, et al. Treatment of gastric cancer with peritoneal carcinomatosis by cytore- 
ductive surgery and HIPEC: a systematic review of survival, mortality, and morbidity. J Surg Oncol 2011; 104: 692-698. [CrossRef]

41. Saito H, Kihara K, Kuroda H, Matsunaga T, Tatebe S, Ikeguchi M. Surgical outcomes for gastric cancer patients with intraperitoneal free cancer cell, but no macroscopic peritoneal metastasis. J Surg Oncol 2011; 104: 534-537. [CrossRef]

42. Glehen O, Gilly FN, Arvieux C, Cotte E, Boutitie F, Mansvelt B, et al. Peritoneal carcinomatosis from gastric cancer: a multi-institutional study of 159 patients treated by cytoreductive surgery combined with perioperative intraperitoneal chemotherapy. Ann Surg Oncol 2010; 17: 2370-2377. [CrossRef]

43. Yang XJ, Huang CQ, Suo T, Mei LU, Yang GL, Cheng FL, et al. Cytoreductive surgery and hyperthermic intraperitoneal chemotherapy improves survival of patients with peritoneal carcinomatosis from gastric cancer: final results of a phase III randomized clinical trial. Ann Surg Oncol 2011; 18: 1575-1581. [CrossRef]

44. Verwaal VJ, van Ruth $\mathrm{S}$, de Bree $\mathrm{E}$, van Sloothen GW, van Tinteren $\mathrm{H}$, Boot $\mathrm{H}$, et al. Randomized trial of cytoreduction and hyperthermic intraperitoneal chemotherapy versus systemic chemotherapy and palliative surgery in patients with peritoneal carcinomatosis of colorectal cancer. J Clin Oncol 2003; 21:3737-3743. [CrossRef]

45. Elias D, Lefevre JH, Chevalier J, Brouquet A, Marchal F, Classe JM, et al. Complete cytoreductive surgery plus intraperitoneal chemohyperthermia with oxaliplatin for peritoneal carcinomatosis of colorectal origin. J Clin Oncol 2009; 27: 681-685. [CrossRef]

46. Shen P, Thai K, Stewart JH, Howerton R, Loggie BW, Russell GB, et al. Peritoneal surface disease from colorectal cancer: comparison with the hepatic metastases surgical paradigm in optimally resected patients. Ann Surg Oncol 2008; 15: 3422-3432. [CrossRef]

47. Quenet F, Goéré D, Mehta SS, Roca L, Dumont F, Hessissen M, et al. Results of two bi-institutional prospective studies using intraperitoneal oxaliplatin with or without irinotecan during HIPEC after cytoreductive surgery for colorectal carcinomatosis. Ann Surg 2011; 254: 294-301. [CrossRef]

48. Klaver YL, Lemmens VE, Creemers GJ, Rutten HJ, Nienhuijs SW, de Hingh $\mathrm{IH}$. Population-based survival of patients with peritoneal carcinomatosis from colorectal origin in the era of increasing use of palliative chemotherapy. Ann Oncol 2011;22: 2250-2256. [CrossRef]

49. Cao C, Yan TD, Black D, Morris DL. A systematic review and metaanalysis of cytoreductive surgery with perioperative intraperitoneal chemotherapy for peritoneal carcinomatosis of colorectal origin. Ann Surg Oncol 2009; 16: 2152-2165. [CrossRef]

50. Terzi C, Yılmaz U, Yakut C, Özbilgin M, Obuz F, Sarıoğlu S, ve ark. Kolorektal kanser kaynaklı peritoneal karsinomatozis olgusunda sitoredüksiyon ve hipertermik intraperitoneal kemoterapi uygulaması ve literatürün gözden geçirilmesi. Ulus Cerrahi Derg 2008; 24: 31-39.

51. Elias D, Benizri E, Pocard M, Ducreux M, Boige V, Lasser P. Treatment of synchronous peritoneal carcinomatosis and liver metastases from colorectal cancer. Eur J Surg Oncol 2006; 32: 632-636. [CrossRef]

52. Bijelic L, Jonson A, Sugarbaker PH. Systematic review of cytoreductive surgery and heated intraoperative intraperitoneal chemotherapy for treatment of peritoneal carcinomatosis in primary and recurrent ovarian cancer. Ann Oncol 2007; 18: 1943-1950. [CrossRef]

53. Trimble EL, Christian MC. Intraperitoneal chemotherapy for women with advanced epithelial ovarian carcinoma. Gynecol Oncol 2006; 100: 3-4. [CrossRef]

54. Deraco M, Baratti D, Laterza B, Balestra MR, Mingrone E, Macrì A, et al. Advanced cytoreduction as surgical standard of care and hyperthermic intraperitoneal chemotherapy as promising treatment in epithelial ovarian cancer. Eur J Surg Oncol 2011; 37: 4-9. [CrossRef]

55. Ryu KS, Kim JH, Ko HS, Kim JW, Ahn WS, Park YG, et al. Effects of intraperitoneal hyperthermic chemotherapy in ovarian cancer. Gynecol Oncol 2004; 94: 325-332. [CrossRef]

56. Cotte E, Glehen O, Mohamed F, Lamy F, Falandry C, Golfier F, et al. Cytoreductive surgery and intraperitoneal chemo-hyperthermia for chemoresistant and recurrent advanced epithelial ovarian cancer: prospective study of 81 patients. World J Surg 2007; 31: 1813-1820. [CrossRef]

57. Guardiola E, Delroeux D, Heyd B, Combe M, Lorgis V, Demarchi M, et al. Intraoperative intra-peritoneal chemotherapy with cisplatin in patients with peritoneal carcinomatosis of ovarian cancer. World J Surg Oncol 2009; 7: 14. [CrossRef]

58. Pavlov MJ, Kovacevic PA, Ceranic MS, Stamenkovic AB, Ivanovic AM, Kecmanovic DM. Cytoreductive surgery and modified heated intraoperative intraperitoneal chemotherapy (HIPEC) for advanced and recurrent ovarian cancer -- 12-year single center experience. Eur J Surg Oncol 2009; 35: 1186-1191. [CrossRef]

59. Helm CW, Richard SD, Pan J, Bartlett D, Goodman MD, Hoefer R, et al. Hyperthermic intraperi-toneal chemotherapy in ovarian cancer: first report of the HYPER-O registry. Int J Gynecol Cancer 2010; 20: 61-69. [CrossRef]

60. Parson EN, Lentz S, Russell G, Shen P, Levine EA, Stewart JH 4th. Outcomes after cytoreductive surgery and hyperthermic intraperitoneal chemotherapy for peritoneal surface dissemination from ovarian neoplasms Am J Surg 2011; 202: 481-486. [CrossRef]

61. Deraco M, Kusamura S, Virzì S, Puccio F, Macrì A, Famulari C ve ark. Cytoreductive surgery and hyperthermic intraperitoneal chemotherapy as upfront therapy for advanced epithelial ovarian cancer: multi-institutional phase-II trial. Gynecol Oncol 2011; 122: 215-220. [CrossRef]

62. Bakrin N, Bereder JM, Decullier E, Classe JM, Msika S, Lorimier G, et al. Peritoneal carcinomatosis treated with cytoreductive surgery and hyperthermic intraperitoneal chemotherapy (HIPEC) for advanced ovarian carcinoma: a French multicentre retrospective cohort study of 566 patients. Eur J Surg Oncol 2013; 39: 1435-1443. [CrossRef]

63. Bollinger DJ, Wick MR, Dehner LP, Mills SE, Swanson PE, Clarke RE. Peritoneal malignant mesothelioma versus serous papillary adenocarcinoma. A histochemical and immunohistochemical comparison. Am J Surg Pathol 1989; 13: 659-670. [CrossRef]

64. Moran B, Baratti D, Yan TD, Kusamura S, Deraco M. Consensus statement on the loco-regional treatment of appendiceal mucinous neoplasms with peritoneal dissemination (pseudomyxoma peritonei). J Surg Oncol 2008; 98: 277-282. [CrossRef]

65. Van der Speeten K, Stuart OA, Sugarbaker PH. Pharmacokinetics and pharmacodynamics of perioperative cancer chemotherapy in peritoneal surface malignancy. Cancer J 2009; 15: 216-224. [CrossRef]

66. Armstrong DK, Bundy B, Wenzel L, Huang $\mathrm{HQ}$, Baergen R, Lele S, et al. Intraperitoneal cisplatin and paclitaxel in ovarian cancer. N Engl J Med 2006; 354: 34-43. [CrossRef]

67. Quenet F, Goéré D, Mehta SS, Roca L, Dumont F, Hessissen M, et al. Results of two bi-institutional prospective studies using intraperitoneal oxaliplatin with or without irinotecan during HIPEC after cytoreductive surgery for colorectal carcinomatosis. Ann Surg 2011; 254: 294-301. [CrossRef]

68. Heiss MM, Murawa P, Koralewski P. The trifunctional antibody catumaxomab fort he treatment of malignant ascites due to epithelial cancer: Results of a prospective randomized phase II/III trial. Int J Cancer 2010; 127: 2209-2221. [CrossRef]

69. Passot G, Dupré A, Rivoire M, Mohamed F, Bakrin N, Glehen O. Intraperitoneal bevacizumab combined with cytoreductive surgery: a pre-clinical study of tolerance and pharmacokinetics in an animal model. Clin Transl Oncol 2012; 14: 931-936. [CrossRef]

70. Information on IP chemotherapy from the Gynecologic Oncology Group (GOG) available online. www.gog.org/IPChemoEd/ipchemoed.html (Accessed on April 26, 2012).

71. Marth C, Walker JL, Barakat RR, Casado A, Gadducci A, Miller B, et al. Results of the 2006 Innsbruck International Consensus Conference on intraperitoneal chemotherapy in patients with ovarian cancer. Cancer 2007; 109: 645-649. [CrossRef]

72. Huang JY, Xu YY, Sun Z, Zhu Z, Song YX, Guo PT, et al. Comparison different methods of intraoperative and intraperitoneal chemotherapy for patients with gastric cancer: a meta-analysis. Asian Pac J Cancer Prev 2012; 13: 4379-4385. [CrossRef]

73. Sun J, Song Y, Wang Z, Gao P, Chen X, Xu Y, et al. Benefits of hyperthermic intraperitoneal chemotherapy for patients with serosal invasion in gastric cancer: a meta-analysis of the randomized controlled trials. BMC Cancer 2012; 12: 526. [CrossRef]

74. Janunger KG, Hafström L, Nygren P, Glimelius B. A systematic overview of chemotherapy effects in gastric cancer. Acta Oncol 2001; 40: 309-326. [CrossRef]

75. Elias D, Honoré C, Dumont F, Ducreux M, Boige V, Malka D, et al. Results of systematic second look surgery plus HIPEC in asymptomatic patients presenting a high risk of developing colorectal peritoneal carcinomatosis. Ann Surg 2011; 254: 289-293. [CrossRef]

76. Sugarbaker PH. Early intervention for treatment and prevention of colorectal carcinomatosis: a plan for individualized care. Surg Oncol Clin N Am 2012; 21: 689-703. [CrossRef]

77. Elias $D$, Goéré $D$, Dumont $F$, Honoré $C$, Dartigues $P$, Stoclin $A$, et al. Role of hyperthermic intraoperative peritoneal chemotherapy in the management of peritoneal metastases. Eur J Cancer 2014; 50: 332340. [CrossRef] 